\title{
The Word-formation of Network in Parody from a Cognitive Perspective
}

\section{Yan-Xin SONG}

\author{
Library of Yingkou Institute of Technology, Yingkou 115012, China; \\ College of Literature, Liaoning University, Shenyang 110036, China
}

Keywords: Parody, The cognitive prototype, Network dictions, Blended Space Theory

\begin{abstract}
There is a large network of language to use parody to generate new word coinage phenomenon, these words can be based on the original term relationship with the new coinage and semantic imitation imitation is divided into two types of formats. From a cognitive perspective, the network language, parody can be understood as the process of coinage to the prototype based on cognitive psychological space synthesis.
\end{abstract}

\section{Introduction}

The emergence of network communication has brought a new social dialect - the network language, the biggest characteristic of which is embodied in the unique lexical system. The formation of this unique vocabulary system is closely related to the specificity of its word-making methods.In the network language, the rhetorical phenomenon and the lexical phenomenon which originally belong to two different aspects of the language are combined together, and the words formed by the rhetorical case in the rhetoric phenomenon are gradually separated from the restriction of the context and transformed into the lexical phenomenon, which is an important way to create network words.There are many figures of speech in Chinese. The most common figure that is used to create new words is imitation, which is also the most important means of network words and phrases. The network words produced by imitation have their cognitive specificity. They are also an important part of network words.

According to the semantic function and cultural connotation of words, the network words have their broad and narrow sense. Words used in a broad sense include terminology related to the network, the special terms related to the network, ans some words and symbols commonly used by netizens on chat and BBS. Network words in a narrow sense only refer to words and symbols used by Internet users in chat rooms and BBS.The network words that we say here refer to the network words with broad sense.According to the broad connotation of the network words, we take the Chinese Network Language Dictionary by Yu Genyuan as our corpus, and investigate the network words which are created though imitation .

\section{Types of Imitation in Network Words}

Chen Wangdao first put forward the rhetorical device of imitation in his book An Introduction to Rhetoric, which was defined as"for satire and ridicule, deliberately imitating the form of special established form is called imitating".In 2001,Xu Guozhen gave a more proper definition of imitation in his book of Parody Research on the basis of the previous generation scholars' definitions. In his opinion, "imitation" is a rhetorical method of "parody" which creates a new temporary statement according to a ready-made language form.Parody is the use of imitation techniques to create new words, that is, copying the existing form of language to create new words and retaining part of the original form of composition.Imitation is the most important word formation method in network language. In network language, new words produced by imitation can be divided into two types according to the relationship between the original words and the new words:

1. Format imitation. Chinese vocabulary often presents an obvious structure in form, which is the format of words. According to certain format, by changing the elements of word, a series of words with the same format can be created.Format parody refers to the method of forming new words by 
means of the typical format in the parody vocabulary system.According to different structures, they can be divided into:

(1)Analogue formula. That is to imitate the format of the prototype words and then make new words by changing first Chinese character.This kind of parody is very common in online languages, like from "bar" to "internet bar", from "fan" to "net fan", from "illiterate" to "net blind", from "smoking cessation" to "quit smoking", from "quit smoking" to "quit the net", from. Pen pal "imitated" "net friend", "years of service" imitation of "net age", "medical ethics" imitation of "net virtue" and so on.

(2) Post-imitation formula.That is to say, imitating the format of the prototype word and then create a new word by changing the latter morpheme.This kind of imitation words are not common in network words, such as "electric shock" imitation "contact net", "bride-to-be" imitation "quasi-hacker", "one country, two systems" imitation "one country two networks".

2. Semantic parody. Semantic parody is to use semantic meaning between words and the relationship between the meaning of paraphrase and other words to create words.According to the semantic differences, semantic parody can be divided into:

(1)Analogue imitation.Parody words and archetypal words have similar meaning by analogy of the same kind of things and belong to the same category.For example, hacker means a person who uses illegal means to evade access control of a computer network system and enters a computer network", by which a series of network words related to an unlawful intrusion network are introduced, such as "red guest", "white guest", "blue guest" and so on.

(2)Contrastive imitation.Parody words have opposite semantic relations with archetypical words, which are formed by replacing antisense morphemes in archetypal words. This kind of word-making method is also one of the most common methods in imitating words, such as "Newbie" to "Old Bird" and "Flying Bird", "Hardware" to "Software", "Intranet" to "Extranet" and so on.

According to the statistics of Chinese Network language Dictionary by Yu Genyuan , the network words included in the dictionary are composed of 22 new words produced by imitation words. The statistics of various subcategories are as follows:

\begin{tabular}{|l|l|l|l|l|}
\hline \multirow{2}{*}{} & \multicolumn{2}{|l|}{ Format imitation } & \multicolumn{2}{l|}{ Semantic imitation } \\
\cline { 2 - 5 } & $\begin{array}{l}\text { Analogue } \\
\text { formula }\end{array}$ & $\begin{array}{l}\text { Post-imitation } \\
\text { formula }\end{array}$ & $\begin{array}{l}\text { Analogy } \\
\text { imitation }\end{array}$ & $\begin{array}{l}\text { Contrast } \\
\text { imitation }\end{array}$ \\
\hline Number & 12 & 4 & 2 & 4 \\
\hline Proportion & $54 \%$ & $18 \%$ & $9 \%$ & $9 \%$ \\
\hline Total & 22 & \multicolumn{3}{l}{} \\
\hline
\end{tabular}

\section{The Cognitive Process of Network Words Imitating}

\section{Extraction of Cognitive prototype of imitating words}

Prototype is the cognitive reference point for categorization of the world. All the concepts are based on the prototype-centered category.Prototype is the best and most typical member of a object category,while the other members have different degrees of typicality to varying degrees. When people produce or acquire basic concept words, they often use prototype as the basis, and judge the basic category of the new object with the help of previous experience and knowledge.

In a sense, parody is a process of conceptualizing things by using linguistic symbols. The whole cognitive process is to fall into the basic category with the aid of speech experience for the object of perception, select from this category and extract cognitive prototype according to relevant requirements. The choice of cognitive archetype is not a simple activity, but a cognitive phenomenon and process in which the cognitive subject based on the existing experience identifies and makes sure the category and finds and determines the prototype.As for imitation words, most of the parody words are familiar to and commonly used by the cognitive subject, and relatively fixed in the process of long-term usage.These words can be seen as cognitive gestalt, each of which consists of some parts, but the gestalt itself is not a simple superposition of each component, but the 
sum of the whole is greater than the part, such as "electric shock","Internet bar","length of service","illiteracy" and so on, all of which have the characteristics of cognitive prototype and the most typical characteristic in its semantic category.

\section{Blended space of Cognition of Imitating Words}

According to the theory of synthetic space in cognitive linguistics, mental space is a small conceptual packet constructed by people in order to achieve the objective of partial understanding and taking actions when they think and talk", that is, a series of concepts have been established through constant thinking and conversation among the cognitive subjects through the new psychological space. The establishment of each mental space is restricted by grammar, context and culture.

In the process of conceptual integration, imitating new network words is mainly involved in four mental spaces: two input spaces, one generic space and one composite space.The four mental spaces are connected to each other by projecting chains to form an integrated conceptual network.In the process of the imitation of network words, prototype properties of created words are in source space.The corresponding target space and the target space belong to different cognitive domains. The source space and target space share the abstract structure and organization . And the core content of cross-space mapping is integrated into class space, that is, class space extracts the backbone structure of two spaces into a generic space, which includes source space and target space structure relationship.After that, the elements in the two domains are selectively projected into the synthesis space, combined with the core content of the class space, and the layer structure is generated under the action of association and analogy to complete the process of imitation words creation.This process can be simply represented in schemas as follows:

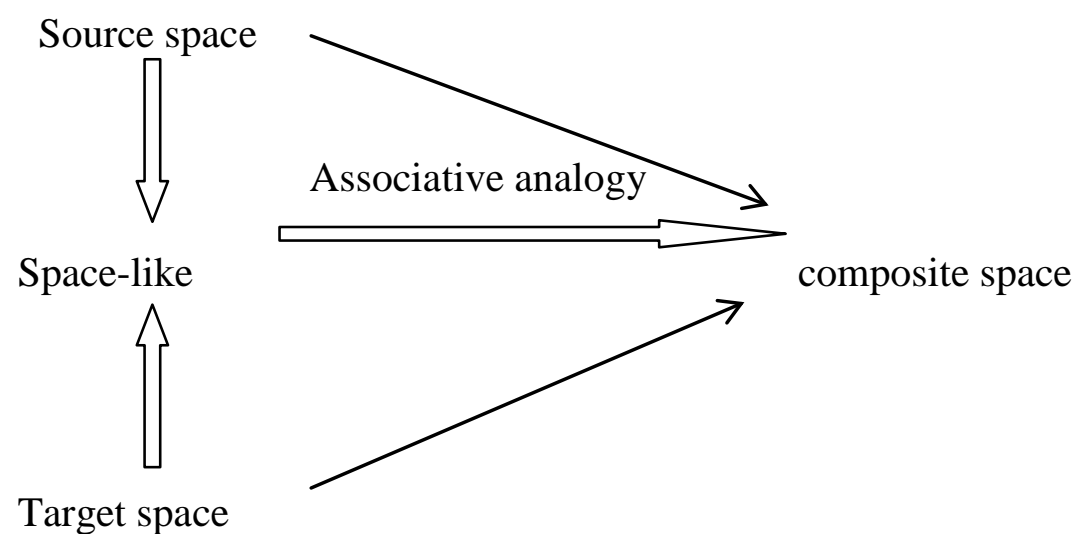

That is how Internet bar evolves from bar, net fan from fan, net blindness from illiteracy, quit Internet from quiting smoking,net friend from pen pal net age,from years of service, net ethics from medical ethics and so on.

Taking Analogue formula as an example. Internet wors like "bar", "fan", "illiterate", "quit smoking", "pen pal", "length of service", "medical ethics" with the features of cognitive prototype are in the source space of blended space.The corresponding target space is the special context of network communication, which is different from the source domain. The source space and the target space project their common abstract structure and organization into the class space, that is, leaving the abstract core contents such as "bar", "mystery", "blindness", "caution", "friend", "age" and "virtue" in the class space.After that, the selected elements in the two-domain space are combined with the core content in the class space, and the hierarchical structure is generated under the action of association and analogy. A series of new network words, such as "internet bar", "net fan", "net blindness", "warning net", "net friend", "net age" and "net virtue", have been created. 


\section{Conclusion}

Figure of speech is not only an important means to improve the effect of language expression, but also an important way to create words.In the network words, quite a few words are created by rhetoric, and imitation is an important figure of speech on creating network words. The whole process of imitation word formation embodies a complete process of blended space. Two input spaces, a generic space and a synthesis space under the influence of the known experience of cognitive subjects create new words which meet the needs of network communication.

\section{References}

[1] Chen Wangdao.An Introduction on Rhetoric.Shanghai:Fudan University Press, (2008)203-204.

[2] Yu Genyuan.Chinese Internet Language Dictionary.Beijing:China Economic Press. 80-90.

[3] Zhao Anfang. An introduction to Cognitive Linguistics.Shanghai: Shanghai Foreign language Education Press.

[4] Fauconnier,G\&M.Turner.Blending as central process of grammer.Ed.Adele Coldberg.Conceptual Structure, Discourse and Language.Stanford:CSLI Publication,1996,50-78.

[5] Lakoff,G\&M.Johnson.Metaphor We Live By.Chicago:The University of Chicago Press,1980,45-74.

[6] F.Ungerer\&H.J.Schmid.An Introduction to Cognitive Linguistics Foreign Language and Research Press Cambridge University Press,2001,78-80. 